\title{
Characterization of tenofovir, tenofovir disoproxil fumarate and emtricitabine in aqueous solutions containing sodium ions usingESI-MS, NMR and $A b$ initio calculations
}

\author{
Kwenga Sichilongo $^{\mathrm{a}^{*}}$,Zibo G. Keolopile ${ }^{\mathrm{b}}$, Scotch Ndlovu ${ }^{\mathrm{a}}$,Elliott MwandoJr ${ }^{\mathrm{a}}$, Chikondi \\ Shaba ${ }^{\mathrm{c}}$ and Amos Massele ${ }^{\mathrm{d}}$ \\ ${ }^{a}$ University of Botswana, Faculty of Science, Department of Chemistry, PB UB00704, Gaborone, \\ Botswana \\ ${ }^{\mathrm{b}}$ University of Botswana, Faculty of Science, Department of Physics, PB UB 00704, Gaborone, \\ Botswana \\ ${ }^{c}$ University of Malawi, Chancellor College, Department of Chemistry, P.O. Box 280, Zomba, \\ Malawi \\ ${ }^{\mathrm{d}}$ University of Botswana, Department of Biomedical Sciences, Faculty of Medicine, PB UB \\ 00713, Gaborone, Botswana
}

\begin{abstract}
We have discerned some characteristics of protonated and sodiated forms of emtricitabine tenofovir and tenofovir disoproxil fumarate in aqueous solutions using mass spectrometry/mass spectrometry (MS/MS), nuclear magnetic resonancespectroscopy (NMR) and $A b$ initiocalculations. Protonated species exhibited different mass spectral characteristics from sodiated species for the three antiretroviral drugs. Sodiation of the three compounds yields extremely stable conformers which require high excitation energies to detach the sodium cation using MS/MS. In the case of emtricitabine (FTC), collision induced dissociation (CID) of the protonated species with $\mathrm{m} / \mathrm{z} 248$ yielded $\mathrm{m} / \mathrm{z} 130$ as the major product ion by losing 2-ethyl-1,3oxathiolane. MS/MS of the sodiated molecular ion [M+Na] $]^{+}$with $\mathrm{m} / \mathrm{z} 270$ would be expected to yield $[\mathrm{M}+\mathrm{H}]^{+}$i.e. $m / z 248$ by losing the $\mathrm{Na}^{+}$cation but instead lost 2-ethyl-1,3-oxathiolane and left the $\mathrm{Na}^{+}$cation well sequestered within the ionic complex.Similar observations were made with tenofovir disoproxil fumarate (TDF) and tenofovir (TFV). Ab initio calculations showed in the case of sodiated TDF and TFV that, the sodium could only be cleaved when a nucleophilic species i.e. $\mathrm{PO}_{2}$ to which it was coordinated to, fragmented requiring activation energy of $1.5 \mathrm{eV}$. The potential energy barrier to remove the $\mathrm{Na}^{+}$cation alone was too high to allow the cleavage to proceed. NMR data showed that when TFV or TDF coordinates with $\mathrm{Na}^{+}$ions at one of the nitrogens at position 1 in the purine moiety of the molecule, it also interacts with oxygens of the phospho group to form an ionic complex and perturbs the chemical environments of several atoms in the periphery. The abundance of sodium cations and their strong interactions with the core structures of FTC, TDF and TFV make sodiated species as the best candidates for their quantitationusing MS/MSespecially in biological fluids. Evidence for improved sensitivity when sodiated species of some of the antiretroviral (ARV) drugs were used for quantitation exists in the literature.
\end{abstract}

Keywords:tenofovir, emtricitabine, ab initio, antiretroviral, sodium, protonated 


\section{Introduction}

Truvada ${ }^{\circledR}$ is a combination of emtricitabine (FTC) and tenofovirdisoproxil fumarate (TDF) and is a nucleoside analog reverse transcriptase inhibitor (NRTI) used for treating HIV-1 in adults and children of age 12 years and above. It contains two drugs and thus can be classified as combination therapy. Dueto its widespread use, it is important to understand the behavior of the individual components of the drug in vitro for purposes of following their fate in humans, the environment in general and also for unravelling critical information necessary to develop accurate and sensitive methods for their detection. Toxicologists in areas such as forensic and analytical sciences may also derive interest in the behavior of thedrugs in humans and the environment. Many analytical methods for the determination of the individual drug components of Truvada ${ }^{\circledR}$ i.e. FTC and TDF have been developed [1-5] and are readily accessible. However, characterization of the two drugs, their metabolites and derivatives in aqueous and non-aqueous phases has not been exhaustedas evidenced by only a handful of such studies found in literature. Anandgaonkaret al.[6] recently reported the characterization of TDF alkaline degradants using LC-MS/MS and 2D-NMR. In this study, the degradation products of TDF were characterized after base hydrolysis using $0.1 \mathrm{~N}$ sodium hydroxide. This study however, did not mimic conditions that exist in vivo under normal circumstances. Theseinclude the presence of speciesthat are of human physiological interest and in abundance in biological fluids such as sodium. In another study, Gomeset al.[7] reported the characterization of TDF using thermal analysis, Fourier transform infrared spectroscopy (FT-IR), solid-state nuclear magnetic resonance (NMR) and powder X-ray diffraction. Emphasis in this study was placed on the variability of temperature and its impact on the structure of TDF especially the fumarate moiety. Here again, the behavior of TDF in solutions containing similar ions as those in biological fluids was not studied particularly the interaction with those ions. Zhou et al. [8] used electron ionization (EI) mass spectra and 1H-NMR to decipher the combination ratio of tenofovir disoproxil (TD) and fumarate (FA) in commercial TDF. This study yielded extremely critical data that would be useful in the pharmaceuticalanalysis of the drug. However, characterization of TDF in solutionscontaining ions such as sodium was also not done. Another research group recently characterized TDF using NMR, ESIMS/MS and other spectroscopic techniques [9]. In that study, they used $\mathrm{D}_{2} \mathrm{O}$ as a NMR solvent and determined proton and carbon- $13\left({ }^{1} \mathrm{H}\right.$ and $\left.{ }^{13} \mathrm{C}\right)$ NMR, Distortionless Enhancement by Polarization Transfer-135 (DEPT-135), Heteronuclear Single Quantum Coherence (HSQC), Heteronuclear Multiple Bond Correlation (HMBC), and Correlation Spectroscopy (COSY) for TDF. In addition, infra-red (IR) and ultravioletspectroscopy were also used in the same study to deduce additional information.

All these studies were focused on TDF in solution and particularly, the protonated form that gives the $[\mathrm{M}+\mathrm{H}]^{+}$ion at $\mathrm{m} / \mathrm{z} 520$ under ESI conditions in mass spectrometry, which was used to unravel the structure of TDF. The sodiated form of TDF that appears at $m / z 542$ under ESI/MS conditions was not of interest and thus was not investigated. From experience in this laboratory, perhaps the sodiated form was not observed because it is difficult to predict all possible products of an analyte in solution prior to an ESI experiment especially for species with multiple reactive functional groups.

${ }^{*}$ Corresponding author.

E-mail address: kwenga.sichilongo@mopipi.ub.bw (Kwenga Sichilongo). 
Protonation, sodiation and generally adduct formation with species of opposite charge, dimerization etc. are all possibilities and thus, these processescan pose challenges [10] where they occur.Recently [11], FTCwas seen to undergo extensive sodiation in solutions containing $\mathrm{Na}^{+}$ions. A comparison of mass spectra obtained using two different mass ranges i.e. one depicting a range that was frequently used in literature but masked the sodiated form at $\mathrm{m} / \mathrm{z} 270$ and one that encompassed $\mathrm{m} / \mathrm{z} 270$. In most of the literature reported for the quantification of FTC, full scan mass spectra were obtained using a mass range of $\mathrm{m} / \mathrm{z} 100$ to around $\mathrm{m} / \mathrm{z} 260$ and this range showed $m / z 248$ i.e. the protonated $[\mathrm{M}+\mathrm{H}]^{+}$ion, as the base peak followed by fragment ions at $m / z 231,152,140$ and 130. Subsequently, $m / z 248$ has been used for quantification of FTC using selected reaction monitoring (SRM) for the transition $248 \rightarrow 130$ [4, 12-14] andin the collision induced dissociation (CID) using $m / z 248$ as precursor ion [15] by quadrupole ion trap (QIT) mass analyzer. This is understood because when a weak acid is used to enhance ionization, off-line protonation is what is expected and not sodiation. However in the case of FTC, when the mass range was widened from $m / z 100-300$ [11], the base peak was $m / z$ 270 which is the sodiated ion i.e. $[\mathrm{M}+\mathrm{Na}]^{+}$, with fragment ionsof insignificant intensities at $\mathrm{m} / \mathrm{z} 248$ and 130with relative abundances of 8 and $7 \%$ respectively. This subsequently led to the examination of $\mathrm{m} / \mathrm{z} 270$ for quantification of FTCwhich gavehigher sensitivity in contrast to literature values where $\mathrm{m} / \mathrm{z} 248$ was used.

While developing methods for possible use in therapeutic drug monitoring (TDM) as well as forensic and toxicological analysis of the drugs in human plasma and the environment, sodiation of tenofovir (TFV) and TDF were also observed in this study. The sodiation was more pronounced in TDF. Thisinspiredfurther investigation into the behavior of the molecules in solutions containing sodium. Further, the fate of the sodiated forms of TFV, TDF as well as FTC in humans and the environment have not been reported exhaustively in literature. Even though "fate" was not the aim of this study, it was felt that, examinationofthe behavior of the sodiated species could stir further interest to pursue them in that dimension. Thus the aim of this work, was to investigate and/or characterize FTC, TFV and TDF, shown in Figure 1, in solutions where both sodiation and protonation were observed using LC-ESI-MS/MS, NMR and Ab initio calculations.

\section{INSERT FIGURE 1}

\section{Materials and Methods}

\subsection{Chemicals and Reagents}

Tenofovir(TFV) (Cat. No. 1643601, Lot FOJ005, Expiry date $31^{\text {st }}$ January 2017)and emtricitabine (FTC)(Cat. 1235106, Lot FOJ163) were USP reference standards purchased from Rockville, MD, USA. Analytical grade TDF and HPLC grade methanol $(\mathrm{MeOH})$ were purchased from Sigma-Aldrich Chemie Gmbh, Munich, Germany. The purity of methanol used throughout the study was $99.9 \%$. LC-MS Chromasolv ${ }^{\circledR}$ is a registered trademark of SigmaAldrich Biotechnology LP and Sigma Aldrich Company. Ultra high purity water used for preparing standards and the mobile phaseswere processed through a MilliQ Ultrapure Ionex Gradient A10 purification system (Millipore Cop, Bedford, MA, USA). A 0.45 $\mu$ m Nylon membrane filter type, HNWP, Millipore (Dublin, Ireland), was used for filtering all organic 
solvents. Mass spectrometry calibration standards Ultramark 1621b, Met-Arg-Phe-Ala i.e. MRFA (98.5 \%) and caffeine (99\%) were purchased from Thermo Scientific Germiston, South Africa.

\subsection{Apparatus and equipment}

\subsubsection{Mass Spectrometry}

The Thermo Scientific Finnigan LCQ DECA Quadrupole Ion Trap Mass Spectrometer with an ESI ion source (Thermo Scientific, San Jose, CA, USA) was used throughout. Analysis of standards and sample extracts was done by direct infusion positive electrospray ionization (ESI). Nitrogen was used as a nebulizer gas and helium as a buffer gas in the quadrupole ion trap (QIT) mass analyzer. The mass spectrometer parameters including vacuum control, the ion optics, main radiofrequency (RF) settings were auto-set by the system. The mass spectrometer was operated in the positive mode. The Thermo/Finnigan Xcalibur software, version 2.0 SR2 (Thermo Scientific, San Jose, CA, USA) software was used for signal acquisition and processing mass spectral data. Direct infusion experiments were done using a syringe pump at a flow rate of 3 $\mu \mathrm{L} / \mathrm{min}$. Theelectron multiplier detector voltage was $-1000 \mathrm{~V}$ throughout. Mass spectrometry/mass spectrometry (MS/MS) were implemented using resonant excitation with a full scale collision induced dissociation (CID) waveform amplitude of $5 \mathrm{~V}$.

\subsubsection{Nuclear Magnetic Resonance (NMR) Spectroscopy}

NMR experiments were performed on a Bruker AG AnlytischeMesstechnikFallanden, Switzerland, Ultrashield $300 \mathrm{MHz} / 54 \mathrm{~mm}$. The $1 \mathrm{D}\left[{ }^{1} \mathrm{H},(300 \mathrm{MHz}) ;{ }^{13} \mathrm{C}(74.5 \mathrm{MHz})\right.$; DEPT135; 2D (COSY, HMQC, HMBC)spectra were acquired on a Bruker Avance DPX spectrometer using deuterated solvents and referenced to residual solvent signals.

\subsubsection{Computational Methods}

A conformation space of sodiated form of structure $M$ was explored by generating a series of possible rotamersusing PESST[16] tool,based on activating major single bonds shown in Figure 1. The generated rotamers were then subjected to full geometrical optimization at Density Functional Theory (DFT) level using Becke's non-local three-parameter, Lee-Yang-Parr, hybrid functional (B3LYP)[17-20] coupled with Pople type 6-31+G* basis set[21]. The resulting optimized structures were arranged according to their decrease in stability followed by visual inspection using Molden[22] package to eliminate those converged into the same minima (similar electronic energies and geometrical parameters). The most stable structure $M$, for example, TDF, was probed with $\mathrm{Na}$ cation at different angles to obtain different possible complexes of sodiated form of TDF, $m / z 542$. The resulting complexes were re-optimized using DFT(B3LYP) functional combined with 6-31+G(3df,3p) basis set. The resulting structures were arranged according to the decrease in their relative stability and the fragmentation pattern of the most stable sodiated form of structure $M$ (in this case, TDF) was investigated further. This was accomplished by scanning the reaction coordinate of interest in series of steps (elongation step size $=0.1 \AA$ ) and each step was followed by partial optimization prior to the next, to obtain the reaction path (in relaxed scan mode). For example, in case of $m / z 542$, we elongated bond 
between atoms labelled 19 and 20 in fig. 1 to map out the potential energy curve and identify stationary points (transition state and local minima) along the surface. The structures of the stationary points and fragments $(\mathrm{m} / \mathrm{z}$ converted structures) were identified and then fully reoptimized at the same computational level of theory followed by frequency calculations.

The activation energies $E_{\text {act }}$ were calculated as,

$$
E_{\text {act }}=E_{T S}^{\text {optimal }}-E_{M}^{\text {optimal }},
$$

where $E_{T S}^{\text {optimal }}$ is the optimal energy of the transition state and $E_{M}^{\text {optimal }}$ is the optimal energy of the sodiated form of structure $M$ whereas the stabilization energy was calculated as,

$$
E_{\text {stab }}=E_{M+N a^{+}}\left(M+N a^{+}\right)-E_{X}(X)-E_{Y}(Y),
$$

where $E_{M}(X)$ and $E_{Y}(Y)$ are the energies of fragments $X$ and $Y$ at their respective optimal geometries. This procedure was repeated for all conversions of $\mathrm{m} / \mathrm{z}$. All the electronic structure calculations in this study were done using Gaussian 09 suite of programs [23] and the molecular structures were drawn using Gauss-view package [24].

\section{Results and Discussion}

\subsection{Mass spectrometry/mass spectrometry (MS/MS) of FTC}

MS/MS was performed on FTC ion (A) $m / z 248$ i.e. $[\mathrm{M}+\mathrm{H}]^{+}$, ion $\mathbf{A}$ in Scheme 1, as the precursor ion using an isolation window of $3 \mathrm{~m} / \mathrm{z}$ units and collision induced dissociation (CID) amplitude of $0.95 \mathrm{~V}$. The product ion was exclusively $\mathrm{m} / \mathrm{z}$ 130, ion 1 as shown in Scheme 1 below.

\section{INSERT SCHEME 1}

The fragmentation pattern suggested in Scheme 1 has previously been observed and reported[2526] but not the sodiated analogue of FTC.Thus, MS/MS was performed on the sodiated form of FTC (B) with $\mathrm{m} / \mathrm{z} 270$ ionB in Scheme 2, as the precursor ion using an isolation window of $3 \mathrm{~m} / \mathrm{z}$ units and a CID amplitude of $1.45 \mathrm{~V}$. The product ion was almost exclusively $m / z 152$, ion 2 as depicted in Scheme 2.

\section{INSERT SCHEME 2}

It was expected that the sodium atom would be cleaved easily at this stage but this turned out not to be the case and so this spurred further exploratory interest. An experiment to characterize the sodiated product ion $m / z 152$ of FTC was performed. In this case the CID amplitudewas incremented from 0.75 to $5.0 \mathrm{~V}$ in steps of $0.25 \mathrm{~V}$. The resultant plot of the ion current of $m / z$ 152 and its subsequent product ion i.e. $\mathrm{m} / \mathrm{z} 133$ are plotted in Figures 2.

\section{INSERT FIGURE 2}

From Figure 2, the optimum CID amplitude for the resonant excitation of $m / z 152$ to form product ion $m / z 133$ i.e. loss of hydrogen fluoride (HF) was $1.5 \mathrm{~V}$. Even at this excitation 
voltage, the intensity of $\mathrm{m} / \mathrm{z} 152$ was 4 times higher than that of $\mathrm{m} / \mathrm{z} 133$. The intensity of $\mathrm{m} / \mathrm{z}$ 152 remained constant from $1.5 \mathrm{~V}$ to about 3.25 Vbefore it dropped to zero. In addition to fragmentation due to resonant excitation, mechanical breakdown of $\mathrm{m} / \mathrm{z} 152$ wassuspected to be responsible for ion current loss after a CIDamplitude of $3.5 \mathrm{~V}$ despite there being no evidence that the sodium ion had been cleavedfrom the product ion. Speculation arose that, the $\mathrm{Na}^{+}$ion sequesters itself in a region of high electron density and imparts stability to the moiety bearing it. In this case, since the pyrimidine moiety bears nitrogen atoms with a high density of electrons, it was suspected as the most likely center for sodium sequestration. After CID of $\mathrm{m} / \mathrm{z} 152$, the product ion $\mathrm{m} / \mathrm{z} 133$ dueto loss of HF, leaves the $\mathrm{Na}$ atom comfortably restrictedwithin the periphery of the pyrimidine moiety of the molecule as seen in Scheme 2. Ab Initio calculations showed that the loss of HF does not occur in a uni-molecular fashion but rather bimolecular whereupon the fluorine (F) atom detaches itself and then attracts a proton from a nearby species. Thus two origins of precursor ions were established giving two different sets of product ions. These were the product ions that originated from the protonated FTC as seen in Scheme 1 and those that originated from the sodiated form as seen in Scheme 2.

\section{2. $M S / M S$ and full scan spectra of TFV $[M+N a]^{+}, m / z 310$ and $[M+H]^{+}, m / z 288$ ions}

MS/MS m/z 310 (ion D in Scheme 4) using an isolation window of $3 \mathrm{~m} / \mathrm{z}$ units and a CID amplitude voltage of $1.5 \mathrm{~V}$ gave product ions $\mathrm{m} / \mathrm{z} 292$ (base peak) which is depicted as ion 7in Scheme 4, which speculatively was due to loss of $\mathrm{H}_{2} \mathrm{O}, \mathrm{m} / z$ 206, 5 and $\mathrm{m} / \mathrm{z}$ 176, 6. The plausible fragmentation pathway is shown in Scheme 3.

MS/MS of $m / z 288$ using an isolation window of $3 \mathrm{~m} / z$ units and a CID amplitude voltage of $2.0 \mathrm{~V}$ gave product ions $\mathrm{m} / z 270$ ion 4 in Scheme 3, which speculatively also was due to loss of $\mathrm{H}_{2} \mathrm{O}, m / z$ 206, 5 and $m / z$ 176, 6. The plausible fragmentation pathway is shown in Scheme 3. $\mathrm{MS} / \mathrm{MS}$

The full scan mass spectrum of TFV gave characteristic ions at $m / z 344,326,310,292,288$ (base peak), 270 (25), 245, 206, 190 and 176. From this set of ions, fragments originating from the sodiated and protonated forms were easily discernible. However, there were two ions i.e. $\mathrm{m} / \mathrm{z}$ 206 and 176 whose origin was not clear at this stage. Additionally $m / z 344$ and 326 appeared to be clusters incorporating several water molecules but this study was beyond the scope the two ions.

\subsection{MS/MS and Full scan spectra of TDF $[\mathrm{M}+\mathrm{H}]^{+}$and $[\mathrm{M}+\mathrm{Na}]^{+}$ions}

Additional experiments involved isolation of the two key originators of the fragment ions in the full scan mass spectrum i.e. $[\mathrm{M}+\mathrm{Na}]^{+} \mathrm{m} / z 542$ and $[\mathrm{M}+\mathrm{H}]^{+}$at $m / z 520$ and followed by $\mathrm{MS} / \mathrm{MS}$ to confirm the identity of the ions. MS/MS was done using $m / z 542$ designated as ion $\mathbf{E}$ in Scheme 4 as the precursor ion, an isolation window of $3 \mathrm{~m} / z$ units and a CID amplitude voltage of $1.5 \mathrm{~V}$. This was followed by MS/MS of $m / z 520$ using an isolation window of $3 \mathrm{~m} / \mathrm{z}$ units and a CID amplitude of 1.6 V. Results of product ions obtained are shown in Table 1. Product ion spectra for $m / z 520$ and 542 are shown in (Figures S1 and S2, Supporting Information). The product ions of $\mathrm{m} / \mathrm{z} 542$ and 520 would thus shed more light on the origins of the ions in the full scan mass spectrum of TDF. The full scan ESI mass spectrum of TDF (Figure S3, Supporting Information)was acquired and showed an intensely sodiated molecular ion at 
$m / z 542$ and protonated ion at $m / z 520$. Other fragment ions which were grouped on the basis of their origin using the product ions of $\mathrm{m} / z 542$ and 520 are shown in Table 1.Thus the two origins of the ions in the full scan mass spectrum were identified on this basis.

Schemes 4 and 5 show plausible fragmentation pathways of $m / z 542$ and $\mathrm{m} / \mathrm{z} 520$ respectively for the product ions that were observed using MS/MS. Note the product ions from ion $\mathbf{C}$ to ion $\mathbf{6}$ i.e. $m / z 176$ in Scheme 5 which originated from protonated species yielding $\mathrm{m} / z 288$ and 270 as product ions. There is also a notable common fragmentation from ion $\mathbf{D}$ to ion $\mathbf{6}$ i.e. $\mathrm{m} / \mathrm{z} 176$ in Scheme 4. This confirmed that both protonated and sodiated forms of the ions i.e. TDF and TFV fragment through pathways that commonly produce $\mathrm{m} / \mathrm{z} 206$ and 176 regardless of their protonation/sodiation status. The protonated and sodiated TDF and TFV fragmentation pathways also showed common ions which can be used as fingerprints to trace the origin of the precursor ions.

\section{INSERT TABLE 1}

\subsection{MS/MS of Sodiated TDF and TFV supported by computation evidence}

Ab Initio calculations showed that there were three types of speciesthat were released during fragmentation of sodiated TDF i.e. $m / z 542$ (E in Scheme 4) upto ion D. These species were $\mathrm{CH}_{2} \mathrm{O}, \mathrm{CO}_{2}$ and $\mathrm{CH}_{2} \mathrm{CHCH}_{3}$. As with FTC, an attempt to cleavethe sodium cation from all ionic species was not successful. The $\mathrm{Na}$ cation reverted and attached itself either adjacent to the nitrogen $(\mathrm{N})$ at position 6, 3 or 8. The most stable state for ion Ewas observed to occur when the $\mathrm{Na}$ cation was adjacent to the $\mathrm{N}$ atom at position 8 and in this optimal geometry, the $\mathrm{Na}^{+}$was coordinated to four atoms, $\mathrm{N}(8), \mathrm{O}(14), \mathrm{O}(31)$ and $\mathrm{O}(34)$ with bond distances of $2.35 \AA, 2.51 \AA$, $2.27 \AA$ and $2.30 \AA$, respectively. These short bond distances indicate strong electrostatic interactionsandthe energy required to remove the $\mathrm{Na}+$ cation washighcompared to detaching groups of other atoms at the ends of the molecule. These four electrostatic interactions were seen in ions $\mathbf{E}$ to $\mathbf{1 0}$ through $\mathbf{8}$ and 9 in Scheme 4. In ions11 and 12, only three interactions were observed and these were from $\mathrm{N}(8), \mathrm{O}(14)$ and $\mathrm{O}(31)$. This was because $\mathrm{O}(34)$ had been released as part of $\mathrm{CH}_{2} \mathrm{O}$. The second electrostatic interaction was observed when the second $\mathrm{CO}_{2}$ was released, i.e. from ion $\mathbf{1 2}$ to $\mathbf{D}$. The first fragmentation was seen to occur when the bond between atoms 19 and 20 in Figure 1, was cleaved. This resulted in the loss of $\mathrm{CH}_{2} \mathrm{O}$ (atoms 18, 19 and hydrogen bonded to 18). During the cleavage, the fragment with atoms bonded to atom 20 could either break further to produce $\mathrm{CO}_{2}$ and $\mathrm{CH}_{3} \mathrm{CHCH}_{3}$ with further lossof a proton from atom 17 to form $\mathrm{CH}_{2} \mathrm{CHCH}_{3}$ because of its instability under gas phase conditions. The fragment could also revertback to the parent ionto form a bond between atoms 17 and 20. This step is governed by the amplitude of the CID voltage in the ion trap. If the energy is low enough for the process to occur, the latter process i.e. reverting to the parent ion supersedes the earlier. If reversion was favored, the resultant was formation of ion $\mathbf{8}$, with $m / z 512$ in Scheme 4.

\section{INSERT SCHEME 4 AND 5}

The activation energy for this step was calculated to be $1.8 \mathrm{eVwhich}$ is much lower than the energy needed to remove $\mathrm{Na}^{+}$, as seen inFigure 3.It is worth noting that, the wall of the potential energy surface is repulsive during the removal of $\mathrm{Na}^{+}$and the surface remains repulsive as it approaches infinite distances. Thebasis functions that were usedin electronic structure 
calculations are finite, therefore, there are inherent limitations to the approach.. As a result, the transition states could be incorrectly described by our basis functions. To avoid this problem, two extreme pointswere considered, well defined by our basis functions. Firstly, when $\mathrm{Na}^{+}$was interacting with TDF and secondly when the two product ionswere isolated. To illustrate the resulting structure $M$ after the removal of $\mathrm{Na}^{+}$e.g. $\mathbf{E}$ ' meaning $\mathbf{E}-\mathrm{Na}^{+}$or simply TDF, prime (') was used. Thus, the stabilization energy for $\mathbf{E}^{\prime}+\mathrm{Na}^{+}$was $3.3 \mathrm{eV}$ which was much greater than both the activation energy $(1.8 \mathrm{eV})$ and/or the stabilization energy $\left(0.9 \mathrm{eV}\right.$ forion $\left.\mathbf{8}+\mathrm{CH}_{2} \mathrm{O}\right)$ when $\mathrm{CH}_{2} \mathrm{O}$ wasreleasedby approximately $1.5 \mathrm{eV}$ and by $2.4 \mathrm{eV}$, respectively. In principle, the activation energy was greater than the stabilization energy. Thus, to remove $\mathrm{Na}^{+}$wouldrequire energy greater than $3.3 \mathrm{eV}$.When the bond between atoms 17 and 18 in Figure 1 is cleaved in ion 8in Scheme 4, atoms 20, 21 and 31 in Figure 1 are released as $\mathrm{CO}_{2}$ and the process is followed by the formation of a bond between atoms 17 and 22 to form Ion 9, with $\mathrm{m} / \mathrm{z} 468$. Efforts to remove the $\mathrm{Na}^{+}$from ion 9 was also not successfuland the stabilization energy for $\mathbf{8}+\mathrm{Na}^{+}$was estimated to be $3.2 \mathrm{eV}$ which is much greater than both the stabilization energy forion $9+\mathrm{CO}_{2}$ ( $0.7 \mathrm{eV}$ )and the activation energy for the release of $\mathrm{CO}_{2}$ by $3.8 \mathrm{eV}$ and by $>2.0 \mathrm{eV}$,respectively. Subsequently, the release of $\mathrm{CO}_{2}$ was preferred over the release of $\mathrm{Na}^{+}$. The last fragmentation occurred when the bond between atoms 17 and 22 in Figure 1, broke. This process released $\mathrm{CH}_{3} \mathrm{CHCH}_{3}$ which was followed by proton transfer from the $\mathrm{CH}_{3}$ group to atom 17 to form $\mathrm{m} / z$ 426, ion10 in Scheme 4, and $\mathrm{CH}_{2} \mathrm{CHCH}_{3}$. The stabilization energy for $9+\mathrm{Na}^{+}$was calculated to be $3.4 \mathrm{eV}$ and the stabilization energy for the formation of Ion $\mathbf{1 0}+\mathrm{CH}_{2} \mathrm{CHCH}_{3}$ was $0.6 \mathrm{eV}$ with an activation energy of $\sim 1.7 \mathrm{eV}$. This also shows that the removal of $\mathrm{Na}^{+}$ion is near impossibleand the release of $\mathrm{CH}_{2} \mathrm{CHCH}_{3}$ wasfavored over the release of $\mathrm{Na}^{+}$. The fragmentation pathway in Scheme 4 repeats for the second moiety of TDF to form ions11, 12 and $\mathbf{D}(\mathrm{TFV}$ discussed below) and releases $\mathrm{CH}_{2} \mathrm{O}, \mathrm{CO}_{2}$ and $\mathrm{CH}_{2} \mathrm{CHCH}_{3}$, respectively, with activation and stabilization energies depicted as Figure 3. The ions that were observed from ion D in Scheme 4 i.e. from TDF, was exactly the same as those observed when sodiated TFV with $m / z 310$ was subjected to CID as described below. The same was observed for protonated TDF as shown in Scheme 5, the only difference being that the $\mathrm{Na}^{+}$cation was not part of the fragmentation pathway. Similar metabolic pathways in human plasma have been reported even though the fragmentation in the QIT would be expected to differ in the absence of physiological control and balance[ 27-29].

\section{INSERT FIGURE 3}

MS/MS of $m / z 310$ i.e. ion $\mathbf{D}$ in the bottom row of Scheme 4, also derived from sodiation of TFV using an isolation window of $3 \mathrm{~m} / \mathrm{z}$ and a CID amplitude voltage of $1.5 \mathrm{~V}$ was also done. The major product ion wasm/z 292 (100) ion 7 with traces of $m / z 206$ (2), ion5 and $m / z 176$ (2), ion 6. The proposed fragmentation pattern is shown in in the bottom row of Scheme 4 . Interestingly, $m / z 206$ and 176 were observed like in the case protonated TFV in Scheme 3. From computational predictions, the stable conformer of the sodiated form of TFV, $m / z 310$, is shown in the bottom row of Figure A1 in the supplementary information. Here, there were six low lying complexes that were observed with energies ranging from 0.0 to $0.8 \mathrm{eV}$, with the one depicted in the bottom row of Figure A4 in supplementary information, being the most stable complex. The $\mathrm{N}(1)$ atom in Figure 1, attacks the $\mathrm{Na}^{+}$cation in solution in a nucleophilic fashion that leads to coordination with $\mathrm{Na}^{+}$and an oxygen atom of the phospho group. The most stable form exhibits relative stabilization energy of approximately $0.5 \mathrm{eV}$ with respect to the next most 
stable structure observed among the low lying complexes. This implies that this complex would be observed in high abundance under mass spectrometric conditions which was apparently visible from the full scan mass spectrum of TFV obtained where its relative abundance was 32 \%. The $\mathrm{Na}^{+}$cation is coordinated toN(8), and $\mathrm{O}(31)$ with bond distances of $2.36 \AA$ and $2.17 \AA$, respectively. The short distances illustrate strong interactions with the lone pairs of nitrogen and the $\mathrm{O}(31)$ of the TFV molecule, thus yielding the most stable structure. Further calculations as seen from Figure 3 (bottom row) confirmed that the energy barrier for detaching $\mathrm{Na}^{+}$from the precursor ion i.e. $\mathrm{m} / \mathrm{z} 310$, was too high compared to that required for the formation of $\mathrm{m} / \mathrm{z} 292$ via loss of a $\mathrm{H}_{2} \mathrm{O}$ molecule depicted as ion 7 in the bottom row of Scheme 4. Further calculations, showed that the resonant CID excitation energy causes one of the $\mathrm{OH}$ groups and a proton from the other $\mathrm{OH}$ group attached to the phosphorous atom to be lost as $\mathrm{H}_{2} \mathrm{O}$ to give an ion with $m / z 292$ i.e. ion 7. There are various minima on conformational space for this ion 7 i.e. $\mathrm{m} / \mathrm{z}$ 292, (Figure S1, Supporting Information) was the most stable conformer. This most stable structure resembled the most stable structure in the $\mathrm{m} / z 310$ series (Figure S4, Supporting Information). This implies that the ionic complex D relaxes to ionic complex 7 upon losing $\mathrm{H}_{2} \mathrm{O}$. The ionic structure 7 is also $>0.1 \mathrm{eV}$ more stable than the next most stable structure out of the four that were observed and thus was observed in high abundance as the base peak (100\%) in the three dimensional QIT mass analyzer.. There still was strong interaction between the $\mathrm{Na}^{+}$ cation and the $\mathrm{N}$ atom at position 1 and one oxygen bonded to the phosphorus atom. The stabilization energy upon fragmentation from $\mathrm{m} / \mathrm{z} 310$ i.e. D to $\mathrm{m} / \mathrm{z} 292$ i.e. 7 was $1.6 \mathrm{eV}$. The next product ion was due to loss of $\mathrm{PO}_{2} \mathrm{Na}$ as seen in the bottom row of Scheme 4to give ion 5 with $m / z 206$. This step can readily beseen from the coordination of the $\mathrm{Na}^{+}$cation to the $\mathrm{PO}_{2}$ group. The sodium was coordinated to $\mathrm{PO}_{2}$ and sat between the two oxygens of $\mathrm{PO}_{2} \mathrm{Na}$ with bond lengths of $2.23 \AA$ from each phospho oxygen. The product ion $\mathrm{m} / z 206$ i.e. ion 5 in Scheme 3 and 4, is very unstable and short lived with a very small activation barrier of $0.1 \mathrm{eV}$. It tautomerizes to from products with relative energies of -1.18 and $-2.2 \mathrm{meV}$ with respect to ion 5 in Scheme 3 and 4. From $m / z 206$ onwards, the product ions are not sodiated and tautomerization is quite common for the unstable structures. Ion $\mathbf{5}$, common in Scheme 3 and 4 i.e. $\mathrm{m} / z 206$ fragments and loses $\mathrm{CH}_{2} \mathrm{O}$ to form $\mathrm{m} / \mathrm{z} 176$ i.e. ion 6 also common in Scheme 3 and 4. That, the $\mathrm{Na}^{+}$cation was cleaved and lost together with the $\mathrm{PO}_{2}$, a strong nucleophile to form $\mathrm{m} / \mathrm{z} 206$ and 176 explained the commonality of both $\mathrm{m} / \mathrm{z} 206$ and 176 in sodiated and non sodiated species of TDF and TFV. It is worth noting that all the reactions were endothermic except during the release of $\mathrm{CO}_{2}$.

\subsection{Addition of $0.1 \mathrm{~N} \mathrm{NaCl}$ solution to a solution of TDF}

An experiment to sodiate the protonated form of TDF in solution was designed. A solution of $0.1 \mathrm{~N} \mathrm{NaCl}$ solution in 50:50 methanol : water was prepared and 48.2 $\mu \mathrm{L}$ were added to $1 \mathrm{~mL}$ of TDF solution also in 50:50 methanol : water at room temperature. This was followed by direct infusion into the mass spectrometer using ESI. Mass spectra in Figure 4A and 4B were obtained. Of particular interest was the reduction in intensity of ions originating from the protonated TDF i.e. $m / z 520$ including fragments related to it seen in Figure 4A. Although 
sodiation did not proceed to completion i.e. $100 \%$, strong sodiation of TDFwas observed together with formation of ions related to iti.e. $m / z$ 542, 468, 426, 396, 352, 310 and 292, as seen in Figure 4B. These ions were exactly the same as those previously obtained by MS/MS of sodiated TDF $m / z 542$ shown in Table 3. The solution was evaporated to dryness and taken up with deuterated dimethyl sulfoxide (DMSO-d6) followed by NMR experiments. This was done in order to discern which chemical environment(s) had been compromised the most by the introduction of $\mathrm{Na}^{+}$ions which in turn would confirm where the $\mathrm{Na}$ was sequestered. Table 4 shows the results obtained from these experiments. Literature values for the NMR of pure TDF in DMSO-d6 without sodiation from two previous studies are also given in the same table.

\section{INSERT FIGURE 4}

\subsection{NMR data obtained before and after sodiation of TDF}

\section{INSERT TABLE 2}

From the proton $\left({ }^{1} \mathrm{H}\right)$ NMR chemical shifts in Table 2 while the raw proton NMR spectra are given (Figure S2 and S3, Supporting Information). Table 2 also shows literature values of pure TDF in DMSO-d6. As seen from Table 4, the highest perturbation of chemical environments(in brackets are the chemical shift changes, $\Delta \delta$, before and after addition of $0.1 \mathrm{~N} \mathrm{NaCl}$ )occurred at position $13(0.032)$ followed by position $11(0.029)$ and then 22 and $29(0.023)$, position 18 and 25 (0.021). The highest chemical shift change occurred at the two protons attached to the nitrogen $\mathrm{N}(13)$ on the purine structure with a chemical shift change before and after sodiation of 0.032 . Generally upfield shifts were observed when sodium was introduced into the TDF. This was expected since metallic species tend to shift chemical shifts upfield as opposed to highly electronegative species which favor downfield shifts. ${ }^{13} \mathrm{C}$ chemicalshift changes between the sodiated and non-sodiated TDF were very significant for carbons at position 22, and 29 which was 1.4 , at positions 12,10 and 5 which were all 1.1. These correlations that were observed using correlation spectroscopy (COSY) as seen in Table $2 .{ }^{13} \mathrm{C}$ chemical shifts are given in Table 3.

\section{INSERT TABLE 3}

This confirmed the strong interaction between the sodium cation and the nitrogens of the purine moiety of TDF as speculated with the pyrimidine moiety of FTC. HMBC correlations between $\mathrm{H} 2, \mathrm{H} 7$ and $\mathrm{H} 13$ with a common feature of all lying between the nitrogens in the purine moiety of the molecule were noted. HMQC did not show any correlations with protons at position 13. This was logical considering this is a $\mathrm{j} 1$ or 1 bond $\mathrm{C}-\mathrm{H}$ correlation.

\section{Conclusions}

In solutions containing sodium ions, FTC, TFV and TDF exhibit ions that are characteristics of both protonated and sodiated species. Sequestration of sodium is favored at the high electron density nitrogen atoms in the pyrimidine moiety in the case of FTC and the purine moiety in the case of TFV and TDF as confirmed by NMR and Ab initio calculations. Ab initio calculations 
showed thatthe energy needed detach the $\mathrm{Na}^{+}$ion from the core molecular ion $\mathrm{M}$ of TDF/TFV in each fragmentation pathway span a range of $3.0-4.0 \mathrm{eV}$ although the activation and the stabilization energies during the fragmentation was less than $1 \mathrm{eV}$. The large amount of energy needed to detach the $\mathrm{Na}^{+}$from the parent structure $\mathrm{M}$ i.e. the stabilization energymeant that the activation energy would even be larger and this made it impossible using CID in the QIT. The product ions of the CID of the molecules i.e. FTC, TFV and TDF, depend on which ion is selected as the precursor ion. Due to the strong interactions between the sodium ions and the three ARVs i.e. FTC, TDF and TFV, sodiated molecular ions would be ideal for quantification of the three analytes especially in biological fluids where sodium if found in high abundance. As a matter of fact and in quantitative work, evidence exists that sodiated species give enhanced sensitivity in bio fluids that contain a lot of sodium. Two distinct fragmentation pathways were demonstrated for all the three ARV analytes. Protonated molecular precursor ions produce product ions that are different from sodiated molecular precursor ions.

\section{Acknowledgements}

The computational section used resources of the National Energy Research Scientific Computing Center, which is supported by the office of science of the United States Department of Energy under Contract No. DE-AC02-05CH1 1231.Acknowledgements to the University of Botswana for material support. Scotch Ndlovuthanks the Southern and EasternAfrican Network of AnalyticalChemists (SEANAC) for Financial support. Chikondi Shaba thanks, the University of Malawi and The AfricanDevelopment Bank for financial support. Elliot Mwandothanks the University of Botswana Foundation for Financial support.

\section{References}

[1] M. Simili, C. Carier, A. De Nicol, A. Arauco, M. Scandera, A. Caliano, S. Obnora, G. Di Perry, A. D'Avolio, A LC-MS method to quantify tenofovir urinary concentrations in treated patients, J. Pharmaceut.Biomed. Anal. 114 (2015) 8-11.

[2] A. De Nicolo, M. Simiele, D. Pensi, L. Boglione, S. Allegra, G. Di Perri, A. D'Avolio, UPLC-MS/MS method for the simultaneous quantification of anti-HBV nucleos(t)ides analogs: Entecavir, lamivudine, telbivudine and tenofovir in plasma of $\mathrm{HBV}$ infected patients, J. Pharmaceut.Biomed. Anal. 114 (2015) 127-132.

[3] E. Yamada, R. Takagi, K. Sudo, S. Kato, Determination of abacavir, tenofovir, darunavir, and raltegravir in human plasma and saliva using liquid chromatography coupled with tandem mass spectrometry, J. Pharmaceut.Biomed. Anal. 114 (2015) 390-397.

[4] M. K. Matta, N. R. Pilli, S. J. V. L. N. Rao, A Validated Liquid Chromatography and Tandem Mass Spectrometric Method for Simultaneous Quantitation of Tenofovir, Emtricitabine, and Efavirenz in Human Plasma and Its Pharmacokinetic Application, ActaChromatographica, 27 (2015) 27-39.

[5] M. H. Abdelhay, A. A. Gazy, R. A. Shaalan, H. K. Ashour, Selective RP-HPLC DAD Method for Determination of Tenofovir Fumarate and Emtricitabine in Bulk Powder and in Tablets, ActaChromatographica, 27 (2015) 41-54. 
[6] V. Anandgaonkar, A. Gupta, S. Kona, M.V.N. Kumar Talluria, Isolation, LC-MS/MS and 2D-NMR characterization of alkalinedegradants of tenofovir disoproxil fumarate, J. Pharmaceut.Biomed.Anal. 107 (2015) 175-185.

[7] E. C. de L. Gomes, W. N. Mussel, J. M. Resende, S. L. Fialho, J. Barbosa, E. Carignani, M. Geppi, and Maria I. Yoshida. Characterization of tenofovir disoproxil fumarate and its behavior under heating, Cryst. Growth Des., 15 (4)(2015) 1915-1922.

[8] Z. Hai-yun, C. Xiao-hong, L. Wei, G. Shan-yue, Mass analysis of tenofovir disoproxil fumarate and determination of fumarate combination ratio by NMR Authors: Chinese J. Pharmaceut. Anal., 32 (12), (2012) 2180-2183.

[9] S. Ai-hua, Z, Yan-feng, S, Yi, G.Yua, L. Ning, M. Yue-ping, Spectral analysis and structural elucidation of tenofovir disoproxil fumarate, Chinese J. Magnetic Resonance, 32 (2015) 542-550.

[10] A. P. Bruins, Mechanistic aspects of electrospray ionization, J. Chromatogr. A, 794 (1998) 345-357.

[11] S. M. Ndolo, K. Sichilongo, A. Massele, E. Sepako, S. Vento, An Investigation of Liquid Chromatography-Mass Spectral Attributes and Analytical Performance Characteristics of Tenofovir, FTCricitabine and Efavirenz in Human Plasma J. Anal.Toxicol. 2016;40 (1): 4957.

[12] J.A. Zheng, L. Guida, C. Rower, J. Castillo-Mancilla, A. Meditz, B. Klein, B. J. Kerr, J. Langness, L. Bushman, J. Kiser, P. L. Andersonet, Quantitation of tenofovir and FTCricitabine in dried blood spots (DBS) with LC-MS/MS. J. Pharmaceut. Biomed.Anal. 88, (2014) 144-151.

[13] T. Delahunty, L. Bushman, B. Robbins1, C. V. Fletcher, The simultaneous assay of tenofovir and emtricitabine in plasma using LC/MS/MS and isotopically labeled internal standards, J. Chromatogr. B., 877 (2009) 1907-1914.

[14] W. Kromdijk, S.A. Pereira, H. Rosing, J.W. Mulder, J.H. Beijnen, A.D.R. Huitema, Development and validation of an assay for the simultaneous determination of zidovudine, abacavir, emtricitabine, lamivudine, tenofovir and ribavirin in human plasma using liquid chromatography-tandem mass spectrometry, J. Chromatogr. B., 919-920 (2013) 43-51.

[15] M. Pendela, D. A. Mamade, J. Hoogmartens, A. V. Schepdael, E. Adams, Characterization of emtricitabine related substances by liquid chromatography coupled to an ion trap mass spectrometer, Talanta 82. (2010) 125-128.

[16] Z. G. Keolopile, M. Gutowski, M. Haranczyk, Discovery of Most Stable Structures of Neutral and Anionic Phenylalanine through Automated Scanning of Tautomeric and Conformational Spaces, J. Chem. Theory Comput. 9 (2013) 4374-4381.

[17]A. D. Becke, Density-functional thermochemistry. III. The role of exact exchange, J. Chem. Phys. 1993, 98, 5648-5652. 
[18] C.Lee, W. Yang, R. G. Parr, Development of the Colle-Salvetti correlation-energy formula into a functional of the electron density, Phys. Rev. B: Condens. Matter Mater. Phys. 1988, $37,785-789$.

[19] S. H. Vosko, L. Wilk, M. Nusair, Accurate spin-dependent electron liquid correlation energies for local spin density calculations: a critical analysis, Can. J. Phys. 1980, 58(8), 1200-1211.

[20] P. J. Stephens, F. J. Devlin, C. F. Chabalowski, M. J. Frisch, Ab Initio Calculation of Vibrational Absorption and Circular Dichroism Spectra Using Density Functional Force Fields, J. Phys. Chem. 1994, 98(45), 11623-11627.

[21]R. Ditchfield, W. J. Hehre, J. A. Pople, "Self-Consistent Molecular-Orbital Methods. IX. An Extended Gaussian-Type Basis for Molecular-Orbital Studies of Organic Molecules". J. Chem. Phys. 54 (2): (1971) 724-728.

[22] G. Schaftenaar and J. H. Noordik,Molden: a pre- and post-processing program for molecular and electronic structures J Comput Aid Mol Des 14, 123 (2000).

[23]M. J. Frisch, G. W. Trucks, H. B. Schlegel, G. E. Scuseria, M. A. Robb, J. R. Cheeseman, G. Scalmani, V. Barone, B. Mennucci, G. A. Petersson, H. Nakatsuji, M. Caricato, X. Li, H. P. Hratchian, A. F. Izmaylov, J. Bloino, G. Zheng, J. L. Sonnenberg, M. Hada, M. Ehara, K. Toyota, R. Fukuda, J. Hasegawa, M. Ishida, T. Nakajima, Y. Honda, O. Kitao, H. Nakai, T. Vreven, J. A. Montgomery, Jr., J. E. Peralta, F. Ogliaro, M. Bearpark, J. J. Heyd, E. Brothers, K. N. Kudin, V. N. Staroverov, R. Kobayashi, J. Normand, K. Raghavachari, A. Rendell, J. C. Burant, S. S. Iyengar, J. Tomasi, M. Cossi, N. Rega, J. M. Millam, M. Klene, J. E. Knox, J. B. Cross, V. Bakken, C. Adamo, J. Jaramillo, R. Gomperts, R. E. Stratmann, O. Yazyev, A. J. Austin, R. Cammi, C. Pomelli, J. W. Ochterski, R. L. Martin, K. Morokuma, V. G. Zakrzewski, G. A. Voth, P. Salvador, J. J. Dannenberg, S. Dapprich, A. D. Daniels, Ö. Farkas, J. B. Foresman, J. V. Ortiz, J. Cioslowski, and D. J. Fox, Gaussian, Inc., Wallingford CT, 2009.

[24]R. Dennington, T. Keith, J. Millam, GaussView, Version 5;Semichem Inc.: Shawnee Mission, KS, 2009.

[25] M. Pendela, D.A. Mamade, J. Hoogmartens, A. Van Schepdael, E. AdamsCharacterization of emtricitabine related substances by liquid chromatography coupled to an ion trap mass spectrometerTalanta 82 (2010) 125-128.

[26] V. Rodr'1guez Robledo, W. Franklin Smyth A study of the analytical behaviour of selected new molecular entities using electrospray ionisation ion trap mass spectrometry, liquid chromatography,gas chromatography and polarography and theirdetermination in serum at therapeutic concentrationsAnal. Chim.Acta 623 (2008) 221-230.

[26] P. Barditch-Crovo,S. G. Deeks, A. Collier, S. Safrin, D. F. Coakley, M. Miller, B. P. Kearney, R. L. Coleman, P. D.Lamy, L. O.. Kahn, I. Mcgowan, P.S. Lietman, Phase i/ii trial of the pharmacokinetics, safety, and antiretroviral activity of tenofovir disoproxil fumarate in human immunodeficiency virus-infected adults.Antimicrob. Agents Chemother., 45 (2001) 2733-2739.

[28] J. van Gelder, S. Deferme, L. Naesens, E. De Clercq, G. Van Den Mooter, R. Kinget, P. Augustijns, Intestinal absorption enhancement of the ester prodrug tenofovirdisoproxil fumarate through modulation of the biochemical barrier bydefined ester mixtures, Drug Metab. Dispos.30 (2002) 924-930. 
8

[29] J. P.Shaw, C. M Sueoko, R.Oliyai, W. A. Lee, M. N. Arimilli, C. U. Kim, K. C. Cundy, Metabolism and pharmacokinetics of novel oral prodrugs of 9-[(R)-2(phosphonomethoxy)propyl]adenine (PMPA) in dogs. Pharm Res, 14 (1997) 1824-1829.

[30] V. B. Pokharkar, M. R. Jolly, D. D. Kumbhar, Engineering of a hybrid polymer-lipid nanocarrier for the nasal delivery of tenofovir disoproxil fumarate: Physicochemical, molecular, microstructural, and stability evaluation, Eur. J. Pharmaceaut. Sci. 71 (2015) 99111. 
Figure 1

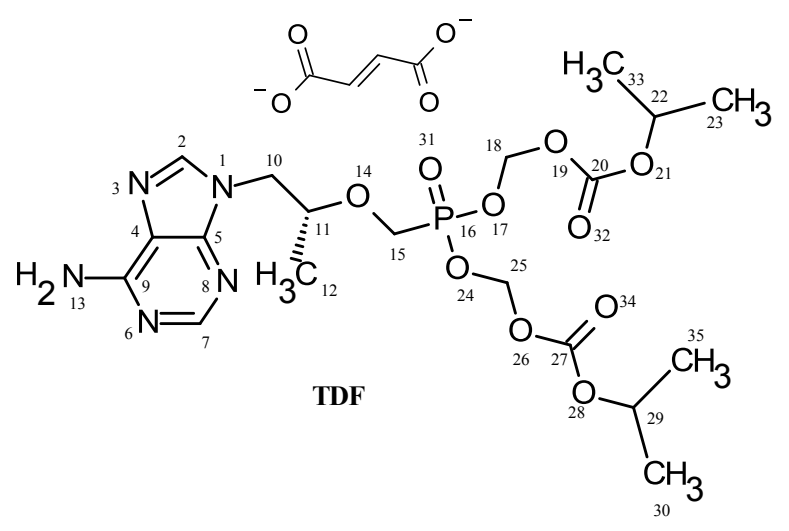

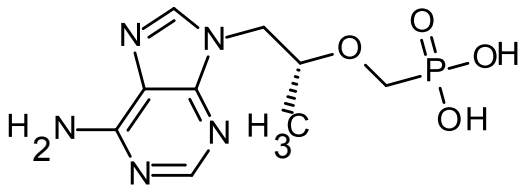

TFV

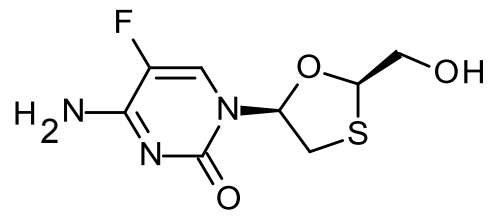

FTC 
Figure 2

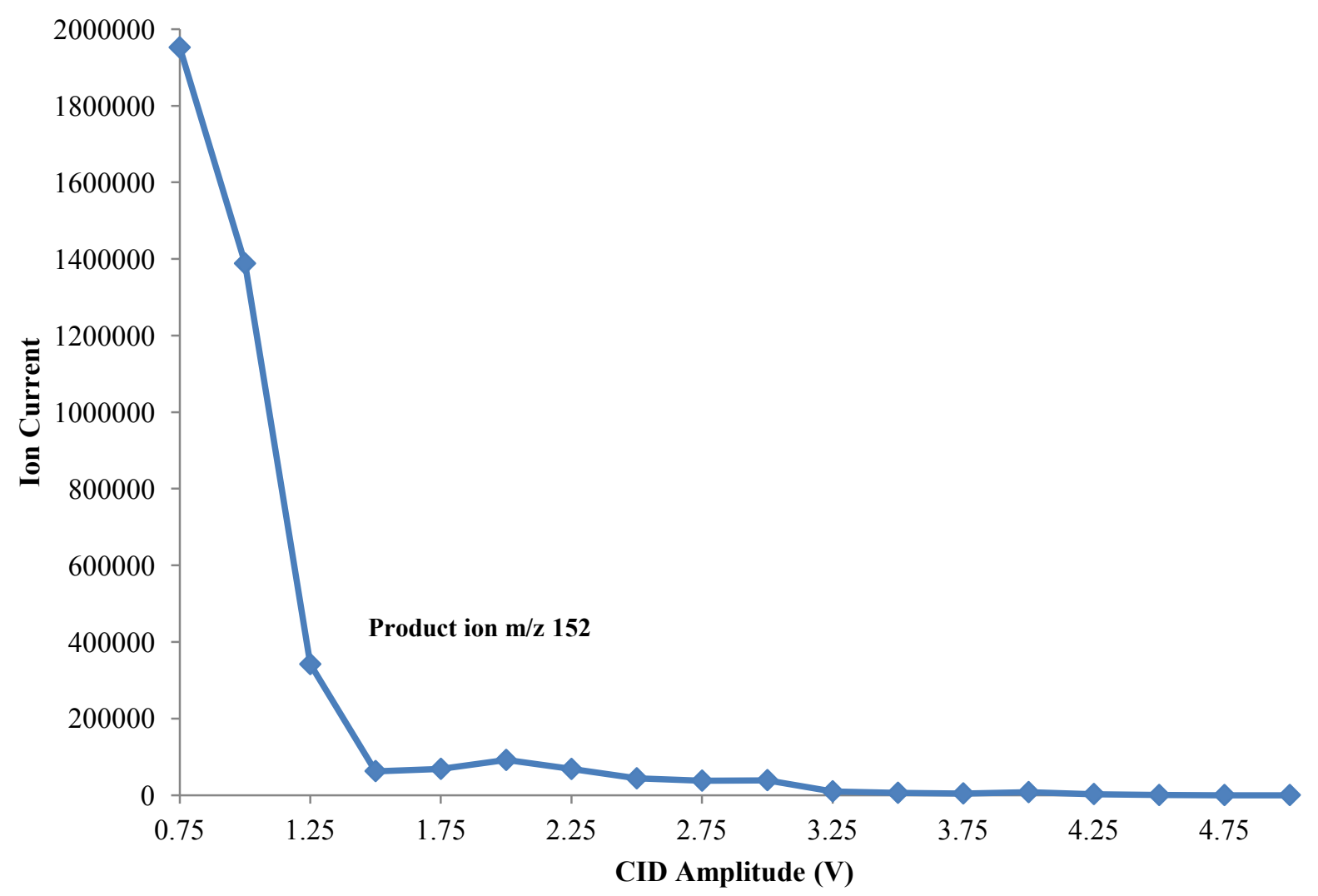


Figure 3

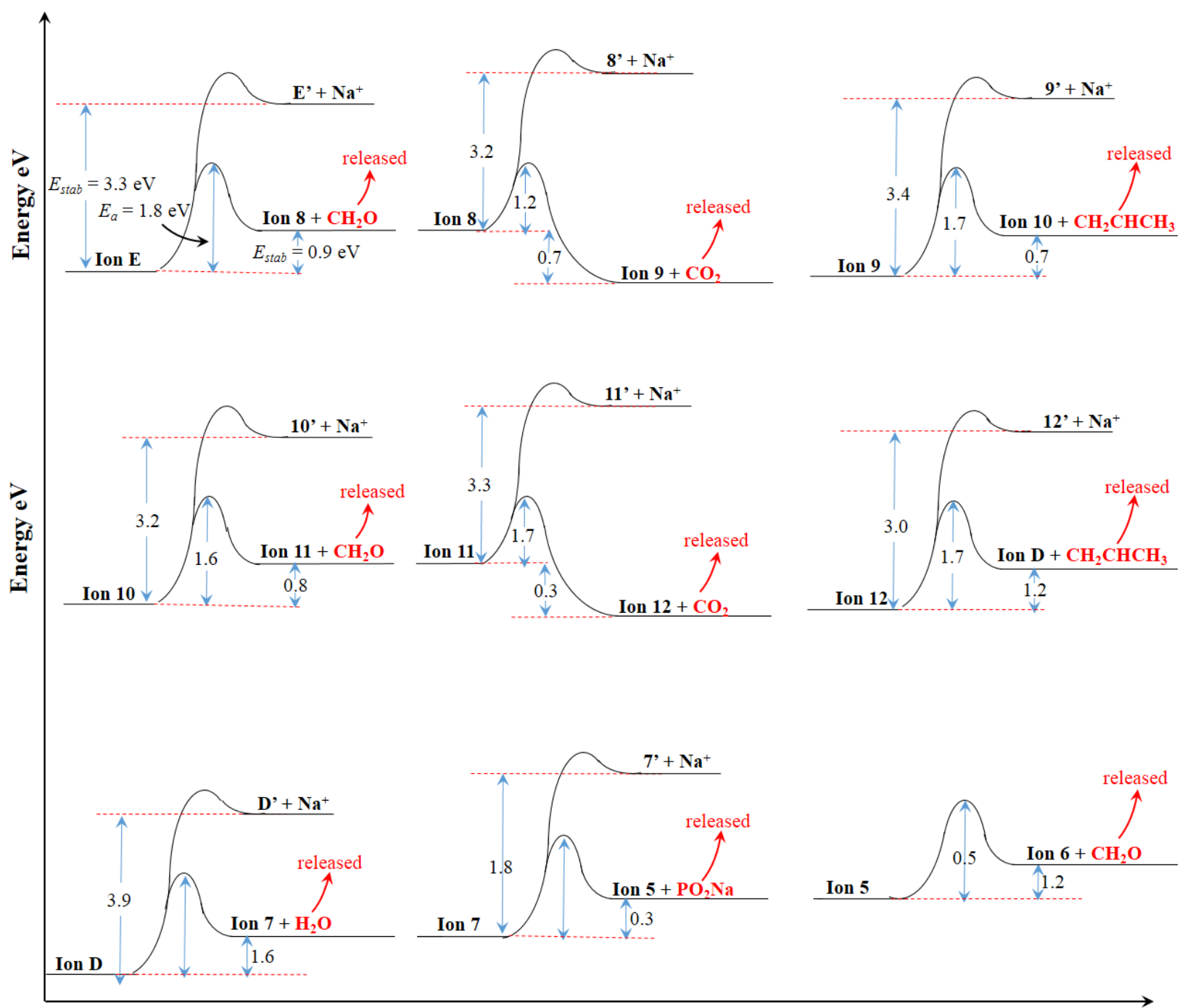

Reaction Coordinate 
Figure 4

A

B
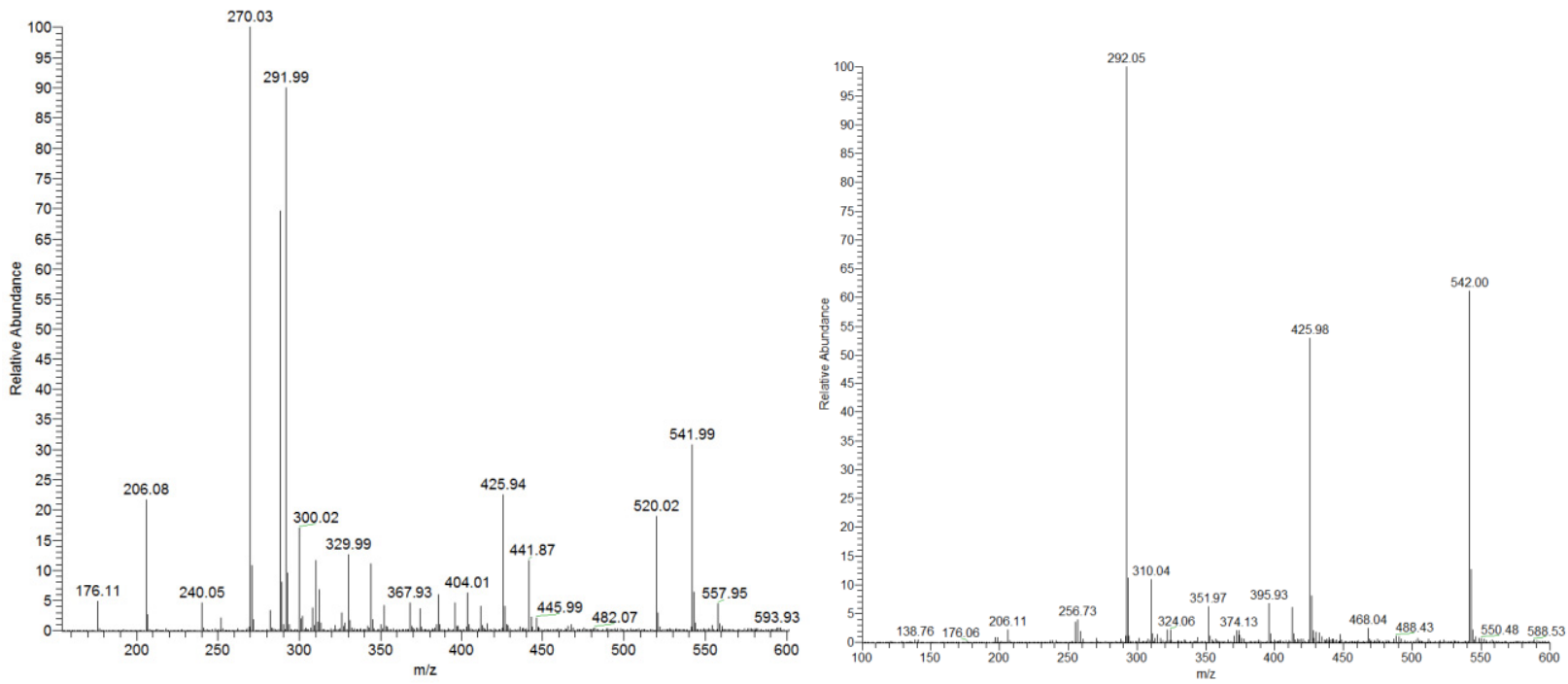
Scheme 1

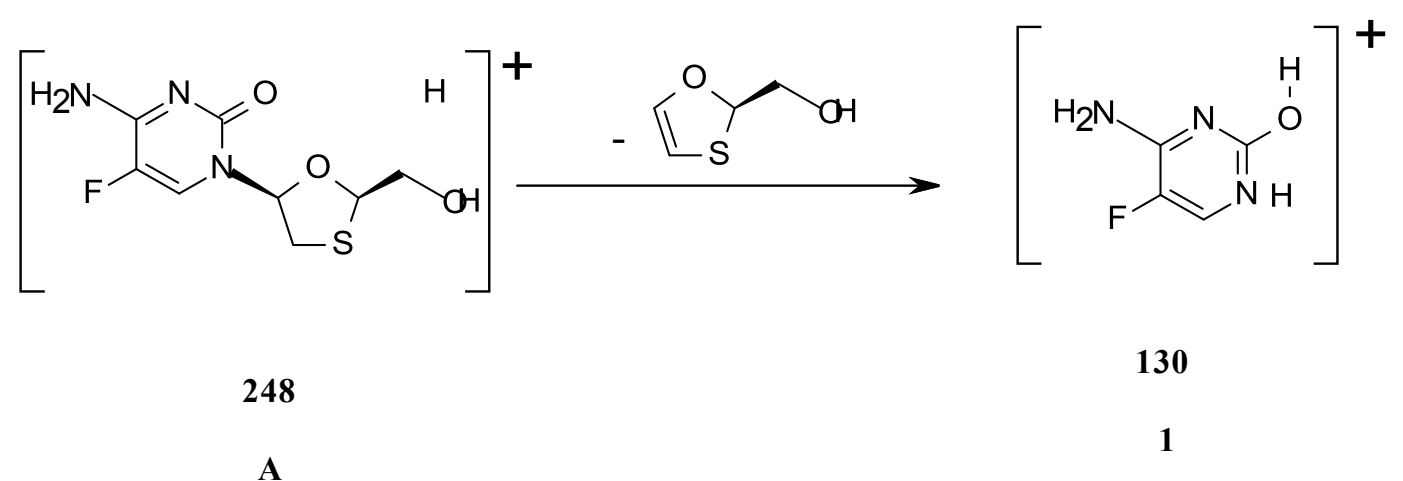


Scheme 2

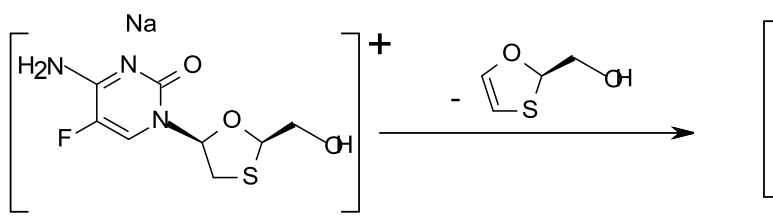

270

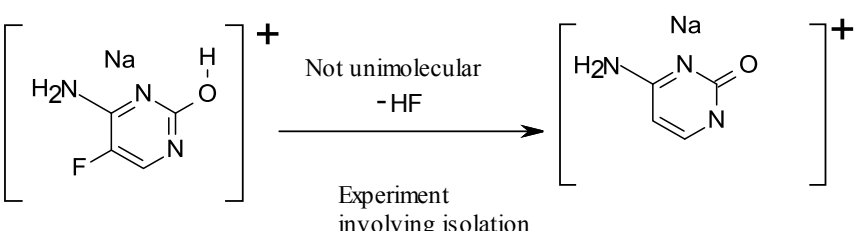

152

involving isolation

133

B

2

3 
Scheme 3

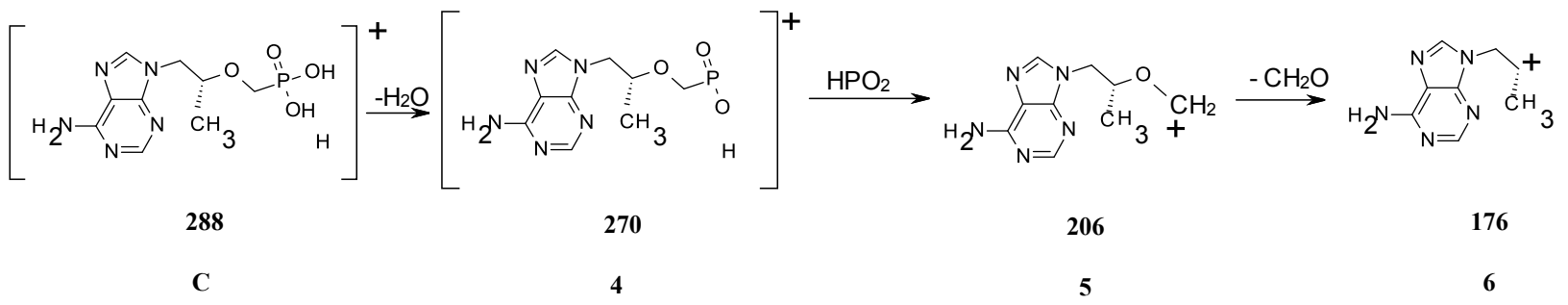


Scheme 4

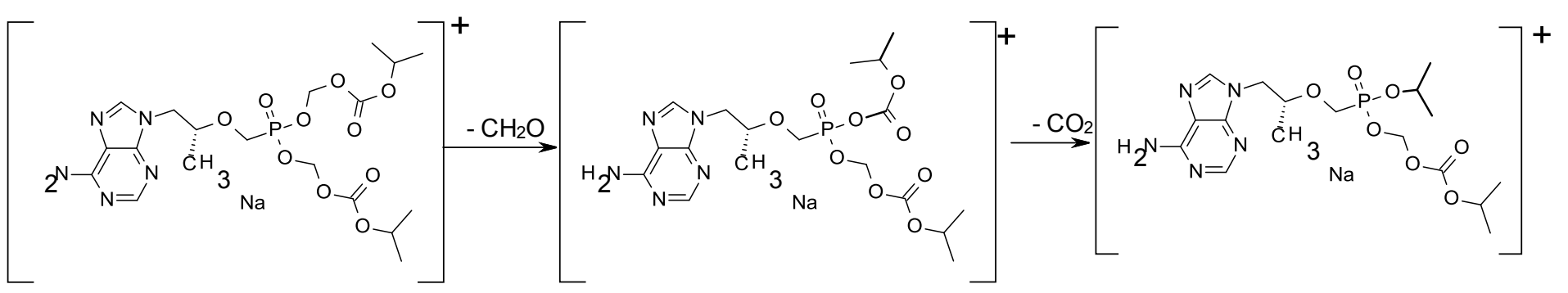

542

512

468

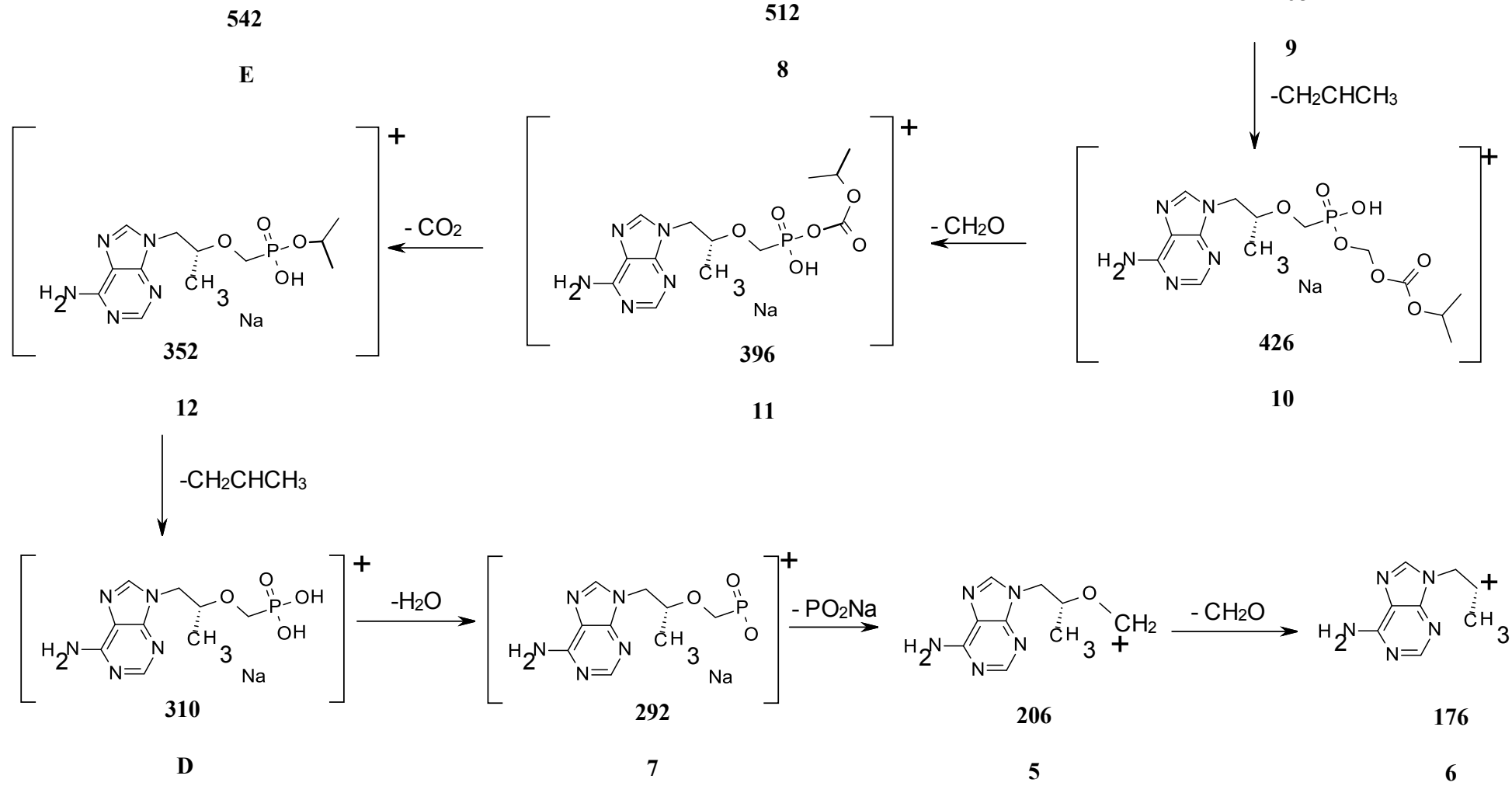


Scheme 5

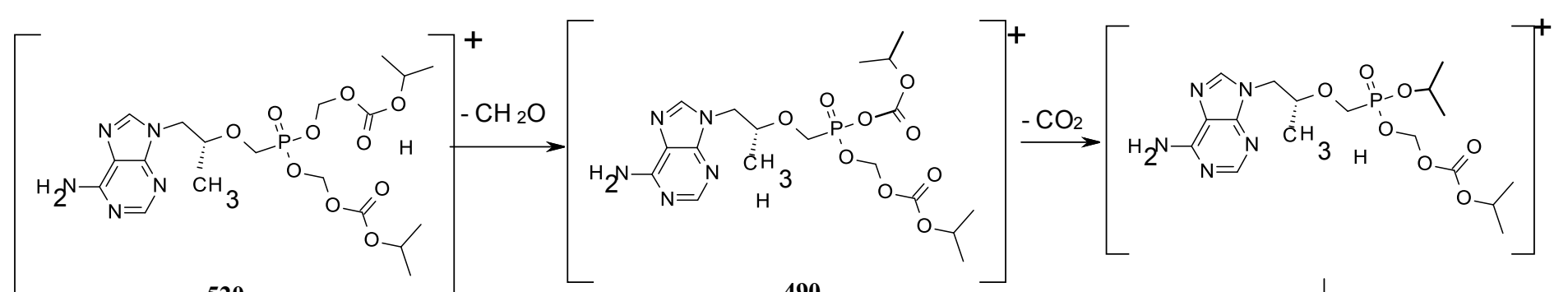

$\begin{array}{lll}520 & \\ \text { F } & -179\end{array}$
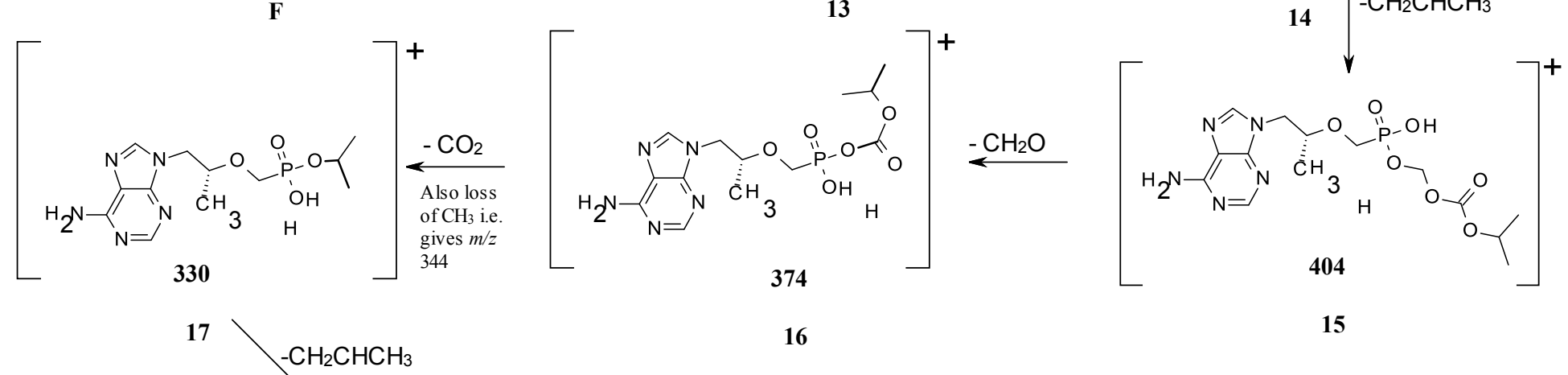

15

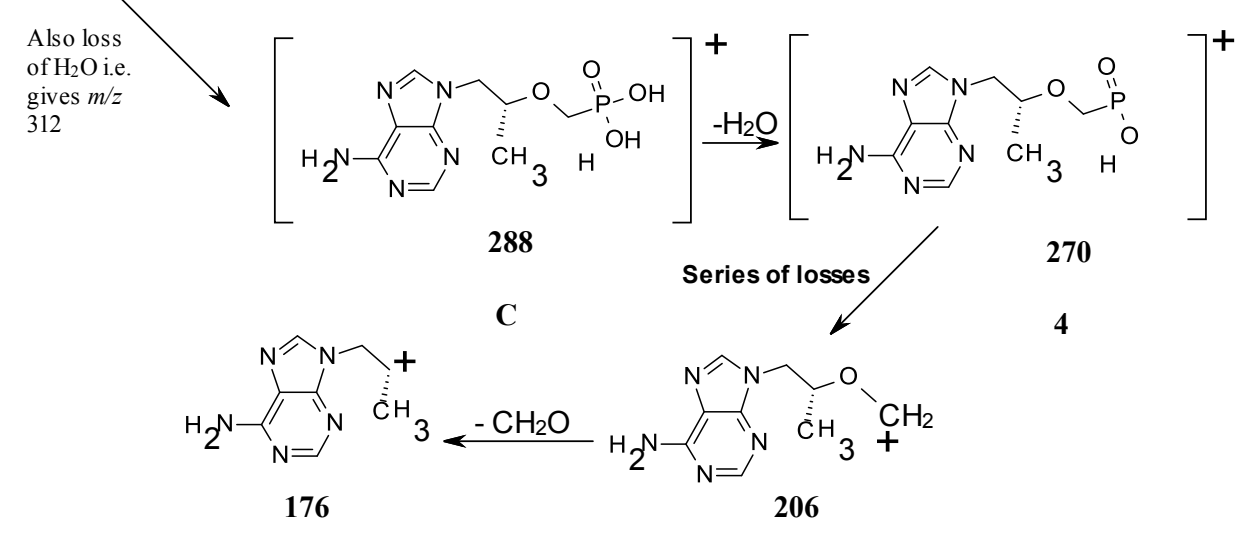

6 
Fig. 1. Structures of tenofovir disoproxil - TDF, tenofovir- TFV and emtricitabine- FTC

Fig. 2. Ion current as a function of CID amplitude in volts (V) for the precursor ion $\mathrm{m} / \mathrm{z} 152$ and the product ion $\mathrm{m} / \mathrm{z} 133$ after loss of a fluorine atom

Fig. 3. (A) Electronic activation energies (eV) for conversion of $\mathrm{m} / \mathrm{z} 542$ to $\mathrm{m} / \mathrm{z} 176$ compared to loss of sodium obtained at B3LYP/6-31+G(3df,3p) level of theory.

Fig. 4. (A) Mass spectrum of TDF before and (B) after addition of $0.1 \mathrm{~N} \mathrm{NaCl}$

Scheme 1. MS/MS of protonated FTC $[\mathrm{M}+\mathrm{H}]^{+}$(A) $\mathrm{m} / \mathrm{z} 248$ giving product ion (1) $\mathrm{m} / \mathrm{z} 130$

Scheme 2. MS/MS of sodiated FTC $[M+N a]+(B) m / z 270$ giving product ion (2) $\mathrm{m} / \mathrm{z} 152$ and product ion (3) after the CID of $\mathrm{m} / \mathrm{z} 152$.

Scheme 3. Plausible fragmentation pathway for $m / z 288$ from TFV

Scheme 4. Plausible fragmentation pathway of sodiated TDF i.e. $[\mathrm{M}+\mathrm{Na}]^{+} m / z 542$

Scheme 5. Plausible fragmentation pathway of protonated TDF i.e. $[\mathrm{M}+\mathrm{H}]^{+} m / z 520$ 
Table 1.

Origins of fragment ions in the full scan mass spectrum of TDF in a solution containing sodium ions

\begin{tabular}{cccc}
\hline $\begin{array}{c}\text { MS/MS of }[\mathrm{M}+\mathrm{Na}]^{+} \\
m / z 542\end{array}$ & $\begin{array}{c}\text { MS/MS of }[\mathrm{M}+\mathrm{H}]^{+} \\
m / z 520\end{array}$ & $\begin{array}{c}\text { Originating from } m / z \\
542\end{array}$ & $\begin{array}{c}\text { in full scan } \\
520 \text { in full scan }\end{array}$ \\
\hline 512 & 490 & 426 & 404 \\
468 & 446 & 396 & 386 \\
426 & 416 & 352 & 374 \\
396 & 404 & 310 & 344 \\
352 & 386 & 292 & 330 \\
310 & 374 & $\mathbf{2 0 6}$ & 312 \\
292 & 344 & $\mathbf{1 7 6}$ & 300 \\
$\mathbf{2 0 6}$ & 330 & & 288 \\
$\mathbf{1 7 6}$ & 312 & & 270 \\
& 300 & & $\mathbf{2 0 6}$ \\
& 288 & & \\
& 270 & & \\
& $\mathbf{2 0 6}$ & & \\
\hline
\end{tabular}


Table 2

Proton $\left({ }^{1} \mathrm{H}\right)$ chemical shifts and COSY NMR of TDF before and after sodiation with $0.1 \mathrm{~N} \mathrm{NaCl}$ solution using the numbering system in the structure in Figure 1 and literature values of proton $\left({ }^{1} \mathrm{H}\right)$ chemical shifts

\begin{tabular}{|c|c|c|c|c|c|c|c|c|c|c|}
\hline \multicolumn{3}{|c|}{ TDF in DMSO-d6 in this study } & \multicolumn{4}{|c|}{ Product of TDF $+0.1 \mathrm{~N} \mathrm{NaCl}$ in DMSO-d6 } & \multicolumn{2}{|c|}{ TDF in DMSO-d6 Ref [6] } & \multicolumn{2}{|c|}{ TDF in DMSO-d6 Ref [ 30] } \\
\hline$\delta(\mathrm{ppm})$ & Position & Multiplicity & $\delta(\mathrm{ppm})$ & Multiplicity & COSY & $\begin{array}{l}\Delta \delta \\
(\mathrm{ppm})\end{array}$ & $\delta(\mathrm{ppm})$ & Multiplicity & $\delta(\mathrm{ppm})$ & Multiplicity \\
\hline $1.072(3 \mathrm{H})$ & 12 & Doublet & $1.057(3 \mathrm{H})$ & Doublet & H11 & 0.015 & $1.1(3 \mathrm{H})$ & Doublet & 1.060 & Doublet \\
\hline 1.249 & $23,30,3$ & Doublet & $1.235(12 \mathrm{H})$ & Doublet & $\mathrm{H} 22, \mathrm{H} 29$ & & $1.3(12 \mathrm{H})$ & Doublet & $1.241-$ & Doublet \\
\hline$(12 \mathrm{H})$ & 3,25 & & & & & 0.014 & & & 1.229 & \\
\hline $3.956(2 \mathrm{H})$ & 15 & $\begin{array}{l}\text { Doublet of } \\
\text { doublets }\end{array}$ & $3.951(2 \mathrm{H})$ & Doublet & - & 0.005 & $3.9(2 \mathrm{H})$ & Multiplet & 3.933 & Multiplet \\
\hline $4.010(1 \mathrm{H})$ & 11 & Doublet & $3.981(1 \mathrm{H})$ & Doublet & H10, H12 & 0.029 & $3.9(1 \mathrm{H})$ & Sextet & $\begin{array}{l}3.955- \\
4.028\end{array}$ & Sextet \\
\hline $4.223(1 \mathrm{H})$ & 10 & $\begin{array}{l}\text { Doublet of } \\
\text { doublets }\end{array}$ & $4.209(1 \mathrm{H})$ & $\begin{array}{l}\text { Doublet of } \\
\text { doublets }\end{array}$ & H11 & 0.014 & $4.2(2)$ & $\begin{array}{l}\text { Two doublet } \\
\text { of doublets }\end{array}$ & $\begin{array}{l}4.193- \\
4.280\end{array}$ & $\begin{array}{l}\text { Two doublet } \\
\text { of doublets }\end{array}$ \\
\hline $4.832(2 \mathrm{H})$ & $22 \& 29$ & Multiplet & $4.809(2 \mathrm{H})$ & Multiplet & $\begin{array}{l}\mathrm{H} 23, \mathrm{H} 33 \& \\
\mathrm{H} 33, \mathrm{H} 35 \\
\text { respectively }\end{array}$ & 0.023 & $4.8(2 \mathrm{H})$ & Septet & $\begin{array}{l}4.792- \\
4.847\end{array}$ & Septet \\
\hline $5.548(4 \mathrm{H})$ & $18 \& 25$ & Septet & $5.527(4 \mathrm{H})$ & Septet & - & 0.021 & $5.5(4 \mathrm{H})$ & Multiplet & 5.583 & Multiplet \\
\hline $6.640(2 \mathrm{H})$ & $\begin{array}{l}\text { Fumaric } \\
\text { acid }\end{array}$ & Singlet & $6.629(2 \mathrm{H})$ & Singlet & - & 0.011 & $6.6(2 \mathrm{H})$ & Singlet & 6.635 & Singlet \\
\hline $7.227(2 \mathrm{H})$ & 13 & Singlet & $7.195(2 \mathrm{H})$ & Singlet & - & 0.032 & $7.2(2 \mathrm{H})$ & Singlet & 7.237 & Singlet \\
\hline $8.041(1 \mathrm{H})$ & 7 & Singlet & $8.046(1 \mathrm{H})$ & Singlet & - & 0.005 & $8.0(1 \mathrm{H})$ & Singlet & 8.034 & Singlet \\
\hline $8.148(1 \mathrm{H})$ & 2 & Singlet & $8.133(1 \mathrm{H})$ & Singlet & - & 0.015 & $8.2(1 \mathrm{H})$ & Singlet & 8.142 & Singlet \\
\hline
\end{tabular}


Table 3.

${ }^{13} \mathrm{C}$ chemical shifts of the protonated TDF from literature and sodiated TDF in this study.

\begin{tabular}{cccc}
\hline & $\begin{array}{c}{ }^{13} \mathrm{C} \text { NMR TDF in DMSO-d6 } \\
\text { Ref [6] }\end{array}$ & $\begin{array}{c}{ }^{13} \mathrm{C} \text { NMR Product of TDF }+ \\
0.1 \mathrm{~N} \mathrm{NaCl} \text { in DMSO-d6 }\end{array}$ \\
\hline Position & $\delta(\mathrm{ppm})$ & $\delta(\mathrm{ppm})$ & $\Delta \delta(\mathrm{ppm})$ \\
\hline $12(1 \mathrm{C})$ & 16 & 17.1 & 1.1 \\
$23,33 \& 30,35(4 \mathrm{C})$ & 21 & 21.7 & 0.7 \\
$10(1 \mathrm{C})$ & 46 & 47.1 & 1.1 \\
$15(1 \mathrm{C})$ & 62 & 61.4 & -0.6 \\
$22 \& 29(2 \mathrm{C})$ & 72 & 73.4 & 1.4 \\
$11(1 \mathrm{C})$ & 76 & 76.4 & 0.4 \\
$18 \& 25(2 \mathrm{C})$ & 84 & 84.7 & 0.7 \\
$4(1 \mathrm{C})$ & 118 & 118.7 & 0.7 \\
$2(1 \mathrm{C})$ & 141 & 142.0 & 1 \\
$5(1 \mathrm{C})$ & 149 & 150.1, & 1.1 \\
$7(1 \mathrm{C})$ & 152 & 152.8 & 0.8 \\
$9(\mathrm{C})$ & 155 & 156.0 & 1 \\
$20 \& 27(2 \mathrm{C})$ & 165 & 164.6 & -0.4 \\
\hline
\end{tabular}

